\title{
Methodological limitations of sociocultural studies of law
}

\author{
Sergey Borisovich Zinkovsky ${ }^{1}$ \\ RUDN University, Law Institute, Department of Theory of Law and State, Moscow, Russia
}

\begin{abstract}
The purpose of the study is to identify the methodological limitations of sociocultural studies of law. The research methods center around the thesis that the sociocultural approach in legal scholarship is most persuasive when implemented in a relatively limited social context. This kind of research is empirical and shows no attention to the creation of explanatory theoretical constructs. The possibilities for comparative legal analysis are also limited because empirical research is primarily descriptive. The result of the study proved that the methods of considering law through the prism of culture are not always able to provide clear tools for analyzing the social factors that determine the features of institutional and procedural differences in law. In addition, the study concludes that the study of law as a cultural phenomenon requires the use of ideal constructions in the process of cognition. On the one hand, it allows operating with concepts whose content is not formally defined. On the other hand, it entails the impossibility of identifying the general principles of the organization of real legal phenomena, the cause-and-effect relationships between them. Foreign sociocultural studies of law often use the concept of "cultural community", the scope of which allows asserting that the subject of research goes far beyond the scope of legal science. The study's novelty lies in an attempt to assess whether the search for cultural foundations of law "blurs" the subject of legal science. The main reason for the "conceptual blurring" of sociocultural studies of law is the lack of a universal, generally recognized approach to defining the concept of culture in Russian and foreign legal science. However, the reductionism of the context of sociocultural studies of law, the use of legal and non-legal concepts and categories cannot always be characterized as unproductive. The revealed methodological limitations of sociocultural studies of law do not prevent the explanation of the actual nature of legal phenomena.
\end{abstract}

Keywords: law as culture, cross-cultural studies, cultural evolution, legal culture, methodological limitations

\section{Introduction}

The background of the study is caused by the opinions found in Russian and foreign literature that the consideration of law as a phenomenon of culture, the search for the cultural foundations of law "blurs" the subject of legal science. It is often noted that "the

\footnotetext{
${ }^{1}$ Corresponding author: Zinkovskiy-sb@rudn.ru
} 
study of legal cultures focuses on the study of the history of the formation of various societies, the specifics of the religious, philosophical, and political views that function in them and the understanding of the law, the state and their interrelationships, ideas about the place of law in the system of social regulation and ways of its legitimation" [1], ignoring or incorrectly describing such phenomena as "the style of legal thinking, the theory and practice of legal argumentation and legal decision-making" [1]. Other studies take contrary positions, suggesting that a sociocultural approach to law can provide a profound explanation of these dogmatic and legal-technical constructs [2].

The purpose of the study is to identify the methodological limitations of sociocultural studies of law. The study's objectives are to determine a) the "points of vulnerability" of the consideration of law as a cultural phenomenon; b) justify the methodological difficulties caused by them, which characterize the sociocultural studies of law. The study hypothesis suggests that the methodological limitations of the sociocultural approach in legal science are concentrated around four questions: 1) how clear criteria can be formulated to distinguish between the legal content of the analyzed phenomena and processes, values, relations, social practices, etc., and other aspects of a non-legal nature; 2) what is the independent cognitive value of legal and non-legal contents taken outside of their relationship; 3) what influence does the limited nature of such a context (historical, ethnic, religious, moral, etc.) have on the study of legal phenomena in a sociocultural context, whether such reductionism contributes to the identification of the actual nature of legal phenomena or, on the contrary, deforms its content; 4) does the idea of culture in legal research imply that the emphasis is placed on the ability of society to reproduce legally significant patterns of social relations, values, etc., or on the ability of these phenomena to constitute, integrate society?

\section{$2 \quad$ Methods}

Since the subject of the study is the methodological limitations of sociocultural studies of law, the methods used are a kind of conceptual premises that provide a sufficient level of abstract-theoretical problematization in combination with specific characteristics of the sociocultural approach in the legal sciences. Studies of law as a cultural phenomenon are most convincing when implemented in a relatively limited social context [3-6]. Such studies draw a large amount of their explanatory potential from detailed historical and cultural material that characterizes social interaction. However, this kind of research is mainly empirical and shows no attention to the creation of explanatory theoretical constructs. The possibilities of comparative legal analysis in this regard are also quite limited since empirical research mainly has descriptive goals [7-9].

Sociocultural research aims to cover, with a certain degree of conditionality, all the political, economic, and social factors and circumstances in which the law functions. The study of law through the prism of the culture and as a cultural phenomenon may be acceptable and necessary in cases where the relationship between legal phenomena and the general cultural context of their existence can be traced quite indistinctly.

\section{$3 \quad$ Results}

The study showed that the methods of considering law through the prism of culture cannot always provide clear tools for analyzing the social factors that determine the features of institutional and procedural differences in law in the legal practice of individual societies and states. 
The study of law as a cultural phenomenon requires the use of ideal constructions in the process of cognition. On the one hand, it allows operating with concepts whose content is not formally defined. On the other hand, it entails the impossibility of identifying the general principles of the organization of real legal phenomena, the cause-and-effect relationships between them.

In foreign studies, the consideration of law as a cultural phenomenon is often accompanied by the use of such a concept as "cultural community", the scope of which allows asserting that the subject of research goes far beyond the scope of legal science.

The main reason for such "conceptual blurring" of sociocultural studies of law is the lack of a universal, generally recognized approach to the definition of the concept of culture in Russian and foreign legal science.

The study results can be displayed in the form of a diagram (Figure 1).

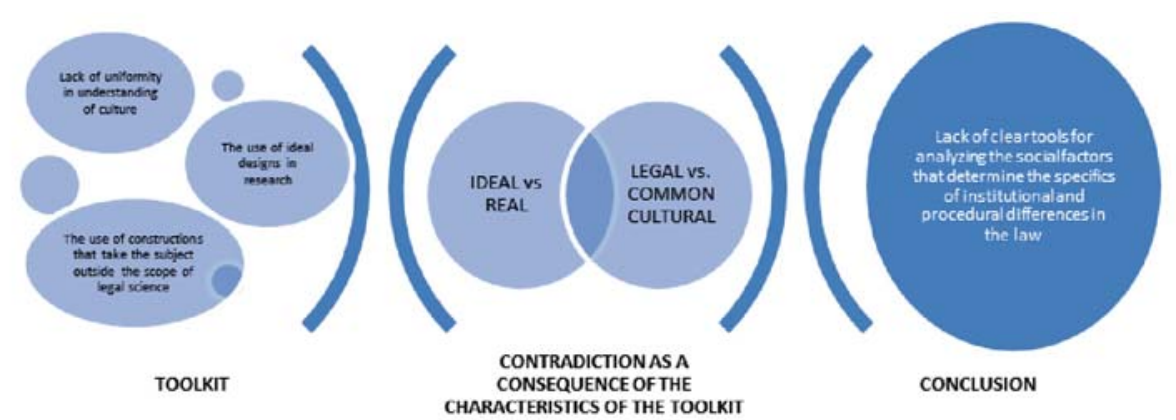

Fig. 1. Methodological limitations of sociocultural studies of law.

\section{Discussion}

The reliability of the research results is confirmed by the analysis of the points of view formed during the consideration of law through the prism of culture in foreign science. For example, R. Cotterrell, analyzing the views of M. Damaska, notes that he operates with the concept of "ideal type", revealing the features of legal families, legal procedures, political structures of society, and its political ideology. M. Damaska generally denies the possibility of any clear formulation regarding the cause-and-effect relationships between social phenomena. He believes that the concept of legal families is unable to fully characterize the distinctive features of legal procedures, first, because of the diversity of legal practice inherent in different systems, even if they are considered as components of a single legal family, and secondly, because of the apparent lack of interrelationships between the procedural elements gathered together as features of a particular legal family [10]. In his opinion, the characteristic of such cultural diversity is possible only in connection with specific historical conditions and a clear periodization of the process of development of society and law. In turn, the process of the historical development of law is inextricably linked with the evolution of ideas about the sociocultural and political-legal structure of society, particularly concerning the peculiarities of the organization of the state and the legitimization of public political power. According to M. Damaska, the logical interrelationships between these ideas create ideal types of legal institutions and procedures, the use of which makes it easier to compare real-functioning legal phenomena in all their diversity. 
Thus, ideal types are logical constructions that aim not to reflect empirical reality but its interpretation. As a result, this gives rise to doubts about the objectivity of the results of the sociocultural study of law based on them - the question arises, what is the researcher dealing with, what is the goal of knowledge in legal science, what, ultimately, is its subject - the actual content of the legal phenomenon or its subjective interpretation?

The concept of "cultural community" was first analyzed in detail in the works of M. Weber. Its use did not imply the materialization or concretization of elements of such generality. According to $\mathrm{M}$. Weber, the cultural community as a kind of ideal construction is a logically connected closed idea created specifically for mental reflection of phenomena; it does not necessarily correspond to a structured empirical reality. A cultural community is only a certain amount of data selected for specific research purposes in a historical and cultural context. The nature and content of this data may vary depending on the purpose of the study. Thus, the concept of "cultural community" is a special case of operating with ideal constructions in the study of legal phenomena from the cultural approach.

The use of ideal constructions allows concluding that culture as a whole and legal culture as its element do not have a measurable empirical existence. Culture is an idea that lends itself only to certain methods of evaluation and observation. For example, in the works of B. Malinovsky, the social structures of the traditional societies studied by him are analyzed, their change and continuity, the typical functional social connections - that is, the researcher quite clearly limited the range of the studied aspects of the culture of small societies of Oceania, which allowed him, albeit at the expense of other aspects, to make the studied cultural community operable and measurable for ethnographic research.

However, when it comes to cultural communities, even with the artificial limitation of the subject of research, science is faced with the "embedding" of various components in this community - the legal content is inseparable from other aspects of culture. That is, the researcher concludes that strictly speaking, there is no legal culture as an independent formalized phenomenon; there is only a culture considered eclectically, in the context of a particular researcher's belief about its legal components dictated by his specific research task.

The paradox is that the attempt to overcome the uncertainty of the scope of the concept of "cultural community" in the characterization of legal culture leads to an unjustified restriction of the subject of legal research. Thus, the problems associated with the ambiguity of the concept of legal culture and with the assessment of causal relationships between its components may, at first glance, seem less acute when considering societies of a certain historical period or when sampling the studied societies according to the regional principle. The legal structure of legal culture will not acquire formal certainty; however, the phenomena that make up this cultural community, being localized in time or space and, as a result, artificially limited in volume, will become more operable in the context of scientific research and measurable. However, this approach will significantly damage the universality of theoretical generalizations as a result of such research.

The "deformation" of the subject of legal science when considering law through the prism of culture can be illustrated by the example of the logic of E. Ehrlich. He believed that differences in attitudes, values, beliefs, and customs could be directly captured in the regulatory diversity that characterizes a particular society. However, among all this diversity, it is quite difficult to isolate the legal component, according to E. Ehrlich - it is necessary to find a concept of culture in which its content would be revealed elementwise and which would represent a theoretical model reflecting the relationship between its elements. Meanwhile, attempts to formulate such a concept in science fail, which is due to the following methodological problems: 
1. The volume of culture as a phenomenon, the diversity of its components and essential characteristics cannot be fully cataloged and reflected in a single definition, especially when researchers, formulating the definition of culture, stand on unconstructive, methodologically limited positions dictated by the political situation [11];

2. The lack of a universal, unified definition of culture in legal science [12] is also explained by the fact that the definitions of culture are formulated mainly on an intuitive rather than on a rational basis [13];

3. The definitions of culture offered by science are based on specific research goals that significantly narrow the range of cultural elements included in the definition, and, as a consequence, the scale of the phenomenon is defined;

4. Research methodological and philosophical positions significantly influence the definition of culture. An example is a difference in emphasis in the study of culture - from the person to sociocentrism, from the spiritual to the material component of culture [14, 15], from joint to separate knowledge of the world and the individual;

5. The methodological difficulties in defining culture are also related to the fact that in the process of its development, it transforms from a mechanism of human adaptation to the natural environment into an environment of a new type in which humanity exists, perceives the priorities, values, and norms dictated by it, and which to a certain extent subordinates biological properties and laws to social ones [16]; in general, the combination of two vectors in the cultural development of the individual, predetermining its behavior biological (instincts, subjective reflection of reality, including legal phenomena, the structure of consciousness, archetypes, unconscious experience) and social - predetermines the difficulties in their distinction and consideration when defining culture.

\section{Conclusion}

The revealed methodological limitations of sociocultural studies of law, however, demonstrate the following: ignoring the fact that "law, being a social phenomenon, is also a cultural phenomenon" [2] is unproductive since describing the law as a cultural phenomenon, the researcher goes to the mechanism of reproduction of legal phenomena with this interpretation, all the mentioned aspects of the law are included in the subject of legal research. It, in turn, is determined by the subject, whose ideas about the subject of research are limited by the following factors: the boundaries of the object under study [17, 18]; the volume and level of accumulated knowledge; the needs of society in the knowledge of certain aspects of the object; the specifics of scientific approaches based on which the subject constitutes the subject of research; these factors can both narrow and expand the perspective on legal phenomena, but its scope ultimately depends on the researcher. The degree of completeness of the explanation of legal phenomena from the standpoint of the sociocultural approach depends on the philosophical and ideological positions on which the researcher stands. Therefore, even the reductionism of the context of sociocultural studies of law, the use of both legal and non-legal concepts and categories can by no means always be characterized as unproductive, especially when it comes to assessing the prospects of interaction between legal cultures [19-23]. The very methodological limitations of sociocultural studies of law do not prevent identifying the actual nature of legal phenomena.

\section{References}

1. N.V. Varlamova, Modern comparative studies: comparative law or comparative cultural studies? Modern Jurisprudence: the search for methodological foundations, in 
G.I. Muromtseva, M.V. Nemytina (eds.), Materials of the All-Russian Scientific Conference, Moscow, 26 March, 2010, 199 (Moscow, 2011)

2. I.L. Chestnov, Cultural dimension of law, in G.I. Muromtseva, M.V. Nemytina (eds.), Legal Cultures, Zhidkov readings: Materials of the All-Russian Scientific Conference, Moscow, 25 March, 2011, 6-13 (RUDN, Moscow, 2012)

3. A.C. Wolkmer, D.A Ferrazzo, Revista Brasileira de Estudos Politicos, 120, 55-150 (2020). https://doi: 10.9732/P.0034-7191.2020V120P055

4. I.N.P. Budiartha, Journal of Advanced Research in Law and Economics, 11(3), 771-774 (2020). https://doi: 10.14505/jarle.v11.3(49).09

5. E. Mak, N. Graaf, E. Jackson, Utrecht Journal of International and European Law, 34(1), 24-44 (2020). https://doi: 10.5334/UJIEL.452

6. S.O. Akoth, African Studies, 77(2), 189-203 (2018). https://doi: 10.1080/00020184.2018.1452854

7. J. Engberg, International Journal for the Semiotics of Law, 33(2), 263-282 (2020). https://doi: 10.1007/s11196-020-09706-9

8. C.-L. Lin, NTUT Journal of Intellectual Property Law and Management, 9(1), 1-17 (2020)

9. B. Fekete, Maastricht Journal of European and Comparative Law, 25(5), 551-564 (2018). https://doi: 10.1177/1023263X18796978

10. R. Cotterrell, The Concept of Legal Culture, in D. Nelken (ed.), Comparing Legal Cultures (Dartmouth, Aldershot, 1997)

11. A.E. Chuchin-Rusov, Questions of philosophy, 4, 3 (1996)

12. M. Van Hoecke, M. Warrington, International and Comparative Law Quarterly, 47, 496 (1998)

13. A. G. Spirkin, Fundamentals of philosophy, 551 (Politicheskaya literatura Publishing House, Moscow, 1988)

14. A. Chuchin-Rusov, Social Sciences and Modernity, 6, 136 (1995)

15. A.E. Chuchin-Rusov, Bulletin of the Russian Academy of Sciences, 10, 913 (1996)

16. N.N. Veresov, Questions of Philosophy, 12 (2000)

17. K. Gergen, Realities and Relationships: soundings in social construction (Harvard University Press, Cambridge (Mass.), 1994)

18. I.L. Chestnov, Constructing social and legal reality, in Ya.I. Gilinsky (ed.), Constructing deviance, 55-84 (Saint Petersburg, 2011)

19. Z.A. Tusupbekov, N.O. Baygabylov, S.B. Balshikeev, N.A. Orynbasarova, A.A. Tusupbekov, Rivista di Studi sulla Sostenibilita, 2020(1), 459-478 (2020). https://doi: 10.3280/RISS2020-001027

20. D. Sulistianingsih, M.S. Prabowo, Journal of Advanced Research in Law and Economics, 10(8), 2533-2541 (2019). https://doi: 10.14505/jarle.v10.8(46).31

21. T.S. Goldbach, Annual Review of Law and Social Science, 15, 583-601 (2019). https://doi: 10.1146/annurev-lawsocsci-101518-042617

22. D. Shedov, Zhurnal Issledovanii Sotsialnoi Politiki, 17(3), $465-472$ (2019). https://doi: 10.17323/727-0634-2019-17-3-465-472

23. D. Koukiadis, Cyprus Review, 30(2), 85-99 (2018) 